\title{
Spatial distribution of cold-adapted Synechococcus during spring in seas adjacent to Korea
}

\author{
Dong Han Choi ${ }^{1,2}$, Jae Hoon Noh $^{1,2, *}$, Sung Min An ${ }^{1}$, Yu Ri Choi ${ }^{1}$, Howon Lee ${ }^{3}$, Kongtae \\ $\mathrm{Ra}^{4,5}$, Dongseon $\mathrm{Kim}^{4,5}$, TaeKeun $\mathrm{Rho}^{4}$, Sang Heon Lee ${ }^{3}$, Kyung-Tae Kim ${ }^{4,5}$, Kyung-Il \\ Chang $^{6}$ and Jung Ho Lee ${ }^{7}$
}

\author{
${ }^{1}$ Marine Life and Ecosystem Division, Korea Institute of Ocean Science and Technology, Ansan 15627, Korea \\ ${ }^{2}$ Department of Marine Biology, Korea University of Science and Technology, Daejeon 34113, Korea \\ ${ }^{3}$ Department of Oceanography, Pusan National University, Busan 46241, Korea \\ ${ }^{4}$ Marine Environmental Analyses Remediation Division, Korea Institute of Ocean Science and Technology, \\ Ansan 15627, Korea \\ ${ }^{5}$ Department of Integrated Ocean Sciences, Korea University of Science and Technology, Daejeon 34113, Korea \\ ${ }^{6}$ School of Earth and Environmental Sciences, Seoul National University, Seoul 08826, Korea \\ ${ }^{7}$ Department of Biology Education, Daegu University, Gyeongsan 38453, Korea
}

\begin{abstract}
We examined the genetic diversity and abundance of picocyanobacteria using barcoded amplicon sequencing approaches and flow cytometry in the East Sea and the East China Sea to determine the distribution patterns of diversity during spring in seas adjacent to the Korean Peninsula. Synechococcus clades I and IV, which have been known as coldadapted ecotypes, dominated at most stations. However, the relative abundances of the two dominant clades differed in their spatial patterns. Clade I was exclusively dominant in the shelf area of the East China Sea and the north East Sea. However, the dominant genotypes belonging to clade I had different spatial distributions in the two areas and responded oppositely to seawater temperature. The dominance of distinct genotypes under the different ecological conditions suggests the presence of ecologically different ecotypes within the clade. Abundances of clade IV were greater than those of clade I at most stations in the southwest East Sea, showing an apparently different pattern from that of the other areas. A warm-water adapted clade II was observed at significant levels only at stations located in the eastern East China Sea affected by a branch of the warm Kuroshio Current. These results suggest that the physicochemical properties of influencing water masses play an important role in determining the distribution of Synechococcus genotypes.
\end{abstract}

Key Words: diversity; East China Sea; East Sea; Japan Basin; Synechococcus; Ulleung Basin

\section{INTRODUCTION}

Picocyanobacteria play an important role as primary producers in aquatic environments (Li 1994, Liu et al. 1997). Among marine picocyanobacteria, Synechococcus are widely distributed in most of the ocean's surface penetrated by sunlight, ranging from equatorial to subpolar waters (Zwirglmaier et al. 2008, Huang et al. 2012, Choi et al. 2015c). Marine Synechococcus is composed of genetically diverse clades, whose biogeographical dis-
(1) \$ This is an Open Access article distributed under the terms of the Creative Commons Attribution Non-Commercial License (http://creativecommons.org/licenses/by-nc/3.0/) which permits unrestricted non-commercial use, distribution, and reproduction in any medium, provided the original work is properly cited.
Received August 2, 2016, Accepted September 10, 2016

* Corresponding Author

E-mail: jhnoh@kiost.ac.kr

Tel: +82-31-400-6218, Fax: +82-31-408-5934 
tribution has been studied in diverse marine environments (Toledo and Palenik 1997, Rocap et al. 2002, Fuller et al. 2003, Ahlgren and Rocap 2006, Mühling et al. 2006, Haverkamp et al. 2008, Paerl et al. 2008, Choi and Noh 2009, Lavin et al. 2010, Huang et al. 2012). An understanding of how environmental factors regulate the distribution of Synechococcus diversity and the ecological niches of each clade is key for predicting the ecosystem response to global warming and ocean acidification in the world's 'changing oceans.' However, the ecological niches of diverse Synechococcus clades have not been clearly elucidated compared to those of Prochlorococcus (West and Scanlan 1999, Ahlgren and Rocap 2006, Johnson et al. 2006, West et al. 2011). Thus, additional studies of picocyanobacterial diversity and their ecological niches are necessary to improve our understanding of both present and future ocean ecosystems.

The East Sea is a semi-enclosed marginal sea bordered by Korea, Japan, and Russia. Although international research programs to study the circulation of the East Sea, such as those of the Circulation Research of the East Asian Marginal Seas (CREAMS) and Pacific-Asian Marginal Seas (PAMS), have contributed to advancements of our scientific knowledge of the region, including the East Sea, few biological studies have been conducted covering the entire East Sea because most studies have been conducted within the territorial waters and exclusive economic zones of specific countries (Choi et al. 2016, Kim et al. 2016). A recent seasonal study conducted in the Dokdo area showed that Synechococcus is most dominant picocyanobacteria in the East Sea and cold water-adapted clades I and IV and warm water-favoring clade II are dominant Synechococcus in winter / spring and summer / autumn, respectively (Choi et al. 2015a). This seasonal pattern also appear in the East China Sea, despite clade II is found significantly in winter due to influence of a branch current of Kuroshio (Choi et al. 2013). In addition, inflow of Changjiang diluted water can affect Synechococcus diversity in summer in the East China Sea (Choi 2012) and nutrient level is one of main controlling factor of seasonal distribution in the East Sea and the East China Sea (Choi et al. 2013). Thus, temperature, nutrient, and current system are the most important factors determining Synechococcus lineage distribution in seas adjacent to Korea.

In spring 2015, we investigated the northern area as well as southwest area of the East Sea. The investigated area includes the subpolar front, a boundary of water masses originating from the cold Liman Current and the Tsushima Warm Current. These investigations provided an opportunity to understand a distribution pattern of cold-adapted Synechococcus genotypes in different current systems. As an investigation was not performed in the East China Sea in the same year, the data obtained in 2011 was used in this study.

\section{MATERIALS AND METHODS}

\section{Study area and sample collection}

This study was conducted in the East China Sea and the East Sea (Fig. 1). In the East China Sea, samples were obtained from the surface and $20 \mathrm{~m}$ depth at 13 stations in Apr 2011. In the East Sea, seawater was sampled at four to six different depths within the euphotic zone from Apr 10 to May 2, 2015. Investigations in the Ulleung and Japan Basins were conducted on board R/V Eardo and R/V Akademik M. A Lavertiev, respectively. Distribution patterns of sea surface temperature, which is one of most important factors determining picocyanobacterial diversity in oceanic environments (Zwirglmaier et al. 2007, Choi et al. 2013), were very similar in April of the two years (Fig. 1). Seawater samples were collected from the surface using 10-L Niskin bottles attached to a rosette sampler.

\section{DNA extraction, high-throughput sequencing, and data analyses}

Microorganisms in 2-L water samples were harvested on a 0.2- $\mu \mathrm{m}$ Supor filter (Gelman, Ann Arbor, MI, USA) and stored at $-80^{\circ} \mathrm{C}$ after the addition of $1 \mathrm{~mL}$ STE buffer (100 mM NaCl, 10 mM Tris-HCl, 1 mM EDTA, pH 8.0) for DNA analyses. DNA was extracted and purified according to Choi et al. (2015b). The diversity of picocyanobacterial internal transcribed spacer (ITS) sequences was sequenced using GS-FLX Titanium for the East China Sea samples obtained in 2011. For the recent East Sea samples, MiSeq platform was used to obtain ca. 10-times more reads than the 454 platform. However, the difference of sequencing platforms would not make a bias for picocyanobacterial diversity in this study, because the same specific primer sequences were used.

To amplify the picocyanobacterial 16S-23S ITS sequences, picocyanobacteria-specific ITS-af (5'-GGA TCA CCT CCT AAC AGG GAG-3') forward and ITS-ar (5'-GGA CCT CAC CCT TAT CAG GG-3') reverse primer sequences were used (Lavin et al. 2008). Pyrosequencing was conducted using the protocol of Choi et al. (2014) and MiSeq sequencing was performed mainly as described in the 

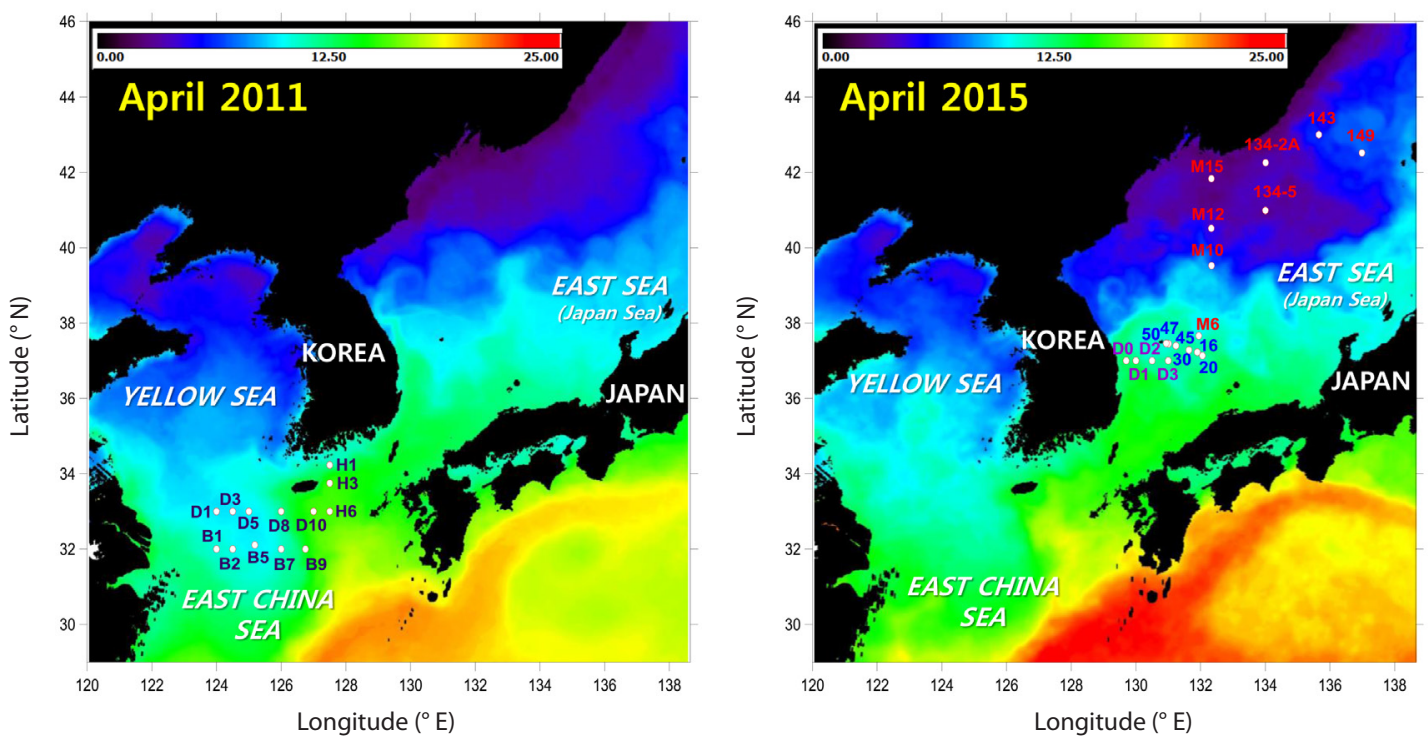

Fig. 1. Maps showing sampling stations of the East China Sea in 2011 and the East Sea in 2015. The base map is a composite image of sea surface temperature for Apr 10-23, 2011 and 2015, respectively, obtained from the moderate-resolution imaging spectroradiometer (MODIS).

MiSeq manual (Illumina 2013). However, Ex-Taq polymerase (Takara, Tokyo, Japan) was used in the polymerase chain reaction (PCR), and the first-round PCR to amplify the picocyanobacterial ITS sequences were conducted using the PCR cycle parameters in Choi et al. (2013). Pyrosequencing of the PCR products was performed using a GS-FLX Titanium system (454 Life Sciences, Branford, CT, USA) at Solgent Co. (Daejeon, Korea), and MiSeq sequencing was performed at ChunLab Inc. (Seoul, Korea).

Following demultiplexing based on the barcode (index) sequences, the obtained sequences were analyzed using the Mothur software program (Schloss et al. 2009). Denoising and trimming of the obtained reads were performed according to the standard operating procedures outlined on the Mothur webpage (http://www.mothur. org). After pooling the remaining reads from the two platforms, downstream analyses were performed using the overall procedures described in Choi et al. (2014). However, the 'chimera.uchime' command was used to identify chimeric sequences, and the 'sub.sample' command was used to normalize the number of reads among samples. The sequences obtained in this study were deposited to the National Center for Biotechnology Information of the US National Library of Medicine (NCBI) sequence read archive (SRA, http://www.ncbi.nlm.nih.gov/Traces/sra; accession number SRP090045).

A phylogenetic tree of the major genotypes (at least one sample $>5 \%$ ) was constructed using the RAxML software program (Stamatakis 2006). A dendrogram describing the similarity of Synechococcus compositions among samples was generated using the theta similarity coefficient (Yue and Clayton 2005) in the Mothur 'tree.shared' command.

\section{Other analyses}

Abundances of Synechococcus were determined by autofluorescence (Olson et al. 2003) using flow cytometry (FACSCalibur or Acury C6; Beckton-Dickinson, Mountain View, CA, USA). Temperature and salinity were measured using a conductivity-temperature-depth sensor (CTD, SBE 9/11 Plus; SeaBird Inc., Bellevue, WA, USA) mounted on a rosette sampler. Chlorophyll $a$ concentration was measured using a Turner field fluorometer (10-AU; Turner Designs, Sunnyvale, CA, USA) after extraction with $90 \%$ acetone (Parsons et al. 1984). Nutrients concentrations were measured using an autoanalyzer and standard colorimetric procedures (Parsons et al. 1984).

\section{RESULTS AND DISCUSSION}

\section{Characteristics of high-throughput sequencing runs}

A total of 82,843 sequences and 540,975 sequences passed the trimming and screening procedures in the analyses of the amplicon libraries of picocyanobacteria using the GS-FLX Titanium and MiSeq platforms, respec- 
tively. The number of sequences per sample ranged from 70 to 24,502 . To reduce bias due to significant variation in the read numbers among samples, the sequence reads of each sample were randomly subsampled at the sampling size of 237 using the Mothur 'sub.sample' command, except for the sample with the smallest read number of 70 (10 m depth of station 30), whose composition was similar to those in adjacent samples (data not shown). Rarefaction analysis showed that the sampling size of 237 would be sufficient to represent the diversity in most of samples (data not shown).

\section{Physicochemical characteristics}

The large variation in sea surface temperature (SST) in the seas adjacent to Korea can be seen in the satellite image in Fig. 1, with the subpolar front situated across ca. $40^{\circ} \mathrm{N}$. Using the SST distribution and CTD data measured in the field, the stations in the East Sea were divided into north East Sea stations (stations at latitudes higher than $40^{\circ} \mathrm{N}$ ) and southwest East Sea stations (stations in the Ulleung Basin and station M10) (Table 1). Similarly, stations H3, H6, D10, and B9 had relatively high SSTs, and were categorized separately from the other stations as eastern East China Sea.

Seawater temperature varied significantly along lines of latitude (Fig. 1). In the north East Sea, which is affected by meltwater, very cold water of $1.9-7.8^{\circ} \mathrm{C}$ was found. In the eastern East China Sea, a maximum water temperature of $17.0^{\circ} \mathrm{C}$ was recorded due to the influence of a branch of the warm Kuroshio Current. However, at stations located in the shelf area (stations B1-B7 and D1-D8), relatively cold water of around $10^{\circ} \mathrm{C}$ was observed. Salinity was low in the shelf area of the East China Sea, and in the north East Sea, indicating an inflow of freshwater from the coast of China and meltwater, respectively (Table 1, Fig. 2). However, in the eastern East China Sea and southwest East Sea, higher salinities $>34$ were observed due to the influence of the oligotrophic saline Tsushima Warm Current. Because water-column stratification was weak or not well-developed during the study period, the general patterns of water temperature and salinity at the subsurface between 20 and $35 \mathrm{~m}$ were similar to those at the surface (Fig. 2).

Macronutrient concentrations were also higher in the areas affected by coastal water (Table 1). However, the concentrations of nitrogen and phosphorus nutrients were lowest in the eastern area of the East China Sea. Chlorophyll $a$ concentrations were also higher in the shelf area of the East China Sea and the north East Sea (Table 1), due to an influence of coastal water and meltwater, respectively.

Table 1. Summary of environmental and Synechococcus variables obtained in each of the study areas

\begin{tabular}{|c|c|c|c|c|}
\hline Variables & $\begin{array}{l}\text { East China Sea } \\
\text { (shelf waters) }\end{array}$ & $\begin{array}{c}\text { East China Sea } \\
\text { (eastern area) }\end{array}$ & $\begin{array}{l}\text { Southwest } \\
\text { East Sea }\end{array}$ & $\begin{array}{l}\text { North } \\
\text { East Sea }\end{array}$ \\
\hline Temperature $\left({ }^{\circ} \mathrm{C}\right)$ & $\begin{array}{c}9.3-13.1 \\
(10.7 \pm 1.2,15)\end{array}$ & $\begin{array}{c}15.7-17.0 \\
(16.5 \pm 0.4,8)\end{array}$ & $\begin{array}{c}9.3-13.6 \\
(11.4 \pm 0.9,51)\end{array}$ & $\begin{array}{c}1.9-7.8 \\
(4.2 \pm 1.7,36)\end{array}$ \\
\hline Salinity & $\begin{array}{c}32.0-34.2 \\
(33.0 \pm 0.7,15)\end{array}$ & $\begin{array}{c}34.5-34.7 \\
(34.6 \pm 0.1,8)\end{array}$ & $\begin{array}{c}33.5-34.5 \\
(34.3 \pm 0.1,51)\end{array}$ & $\begin{array}{c}33.8-34.1 \\
(34.0 \pm 0.1,36)\end{array}$ \\
\hline Nitrate + nitrite $(\mu \mathrm{M})$ & $\begin{array}{c}0.6-9.9 \\
(5.2 \pm 2.9,15)\end{array}$ & $\begin{array}{c}0.5-1.4 \\
(0.9 \pm 0.3,8)\end{array}$ & $\begin{array}{c}0-6.0 \\
(3.1 \pm 2.2,28)\end{array}$ & $\begin{array}{c}0.6-11.1 \\
(5.4 \pm 3.9,23)\end{array}$ \\
\hline Phosphate $(\mu \mathrm{M})$ & $\begin{array}{c}0.04-0.47 \\
(0.28 \pm 0.14,15)\end{array}$ & $\begin{array}{c}0.06-0.12 \\
(0.10 \pm 0.02,8)\end{array}$ & $\begin{array}{c}0-0.31 \\
(0.17 \pm 0.1,28)\end{array}$ & $\begin{array}{c}0.12-0.84 \\
(0.47 \pm 0.26,23)\end{array}$ \\
\hline Chlorophyll $a\left(\mu \mathrm{g} \mathrm{L}^{-1}\right)$ & $\begin{array}{c}0.6-6.1 \\
(1.8 \pm 1.6,15)\end{array}$ & $\begin{array}{c}0.5-0.9 \\
(0.7 \pm 0.1,8)\end{array}$ & $\begin{array}{c}0.3-3.2 \\
(1.3 \pm 0.7,51)\end{array}$ & $\begin{array}{c}0.2-5.6 \\
(2.7 \pm 1.5,36)\end{array}$ \\
\hline $\begin{array}{l}\text { Synechococcus abundance } \\
\left(\times 10^{3} \text { cells } \mathrm{mL}^{-1}\right)\end{array}$ & $\begin{array}{c}0.8-15 \\
(4.8 \pm 4.3,15)\end{array}$ & $\begin{array}{c}0.3-4 \\
(1.4 \pm 1.2,8)\end{array}$ & $\begin{array}{c}0.7-68.4 \\
(15.7 \pm 20.1,51)\end{array}$ & $\begin{array}{c}0.4-8.4 \\
(2.2 \pm 2.4,36)\end{array}$ \\
\hline Clade I (\%) & $\begin{array}{c}81.6-98.8 \\
(92.3 \pm 4.5,15)\end{array}$ & $\begin{array}{c}49.5-89.3 \\
(69.8 \pm 14.5,8)\end{array}$ & $\begin{array}{c}13.4-78.2 \\
(47.8 \pm 19.5,51)\end{array}$ & $\begin{array}{c}84-99.1 \\
(94.2 \pm 3.6,36)\end{array}$ \\
\hline Clade II (\%) & $\begin{array}{c}0-1.6 \\
(0.3 \pm 0.5,15)\end{array}$ & $\begin{array}{c}3.3-43.7 \\
(22.7 \pm 14.6,8)\end{array}$ & $\begin{array}{c}0-38.1 \\
(1.4 \pm 5.9,51)\end{array}$ & $\begin{array}{c}0-0.9 \\
(0 \pm 0.2,36)\end{array}$ \\
\hline Clade IV (\%) & $\begin{array}{c}1.2-17.2 \\
(7.3 \pm 4.2,15)\end{array}$ & $\begin{array}{c}1.6-9.7 \\
(5.9 \pm 2.6,8)\end{array}$ & $\begin{array}{c}18.6-79.5 \\
(50.5 \pm 19.6,51)\end{array}$ & $\begin{array}{c}0.9-11.5 \\
(5.6 \pm 3.3,36)\end{array}$ \\
\hline
\end{tabular}

Clade percentages represent the relative percentages of sequences belonging to Synechococcus clades I, II, and IV among all picocyanobacterial sequences. The data are shown the range and mean values (mean \pm standard deviation, number) of the variables. 


\section{Surface}
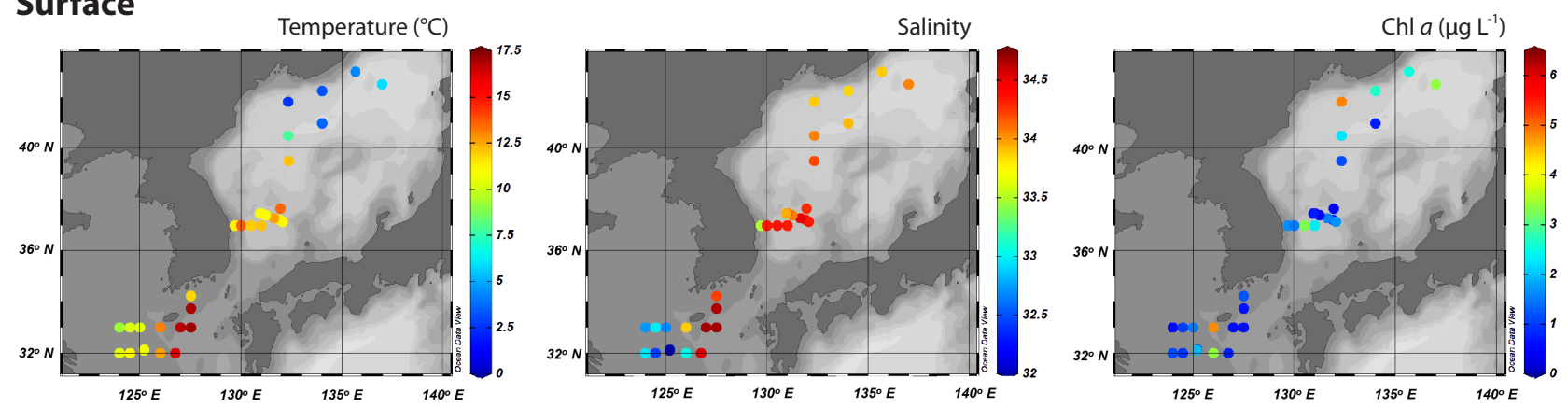

\section{Subsurface}
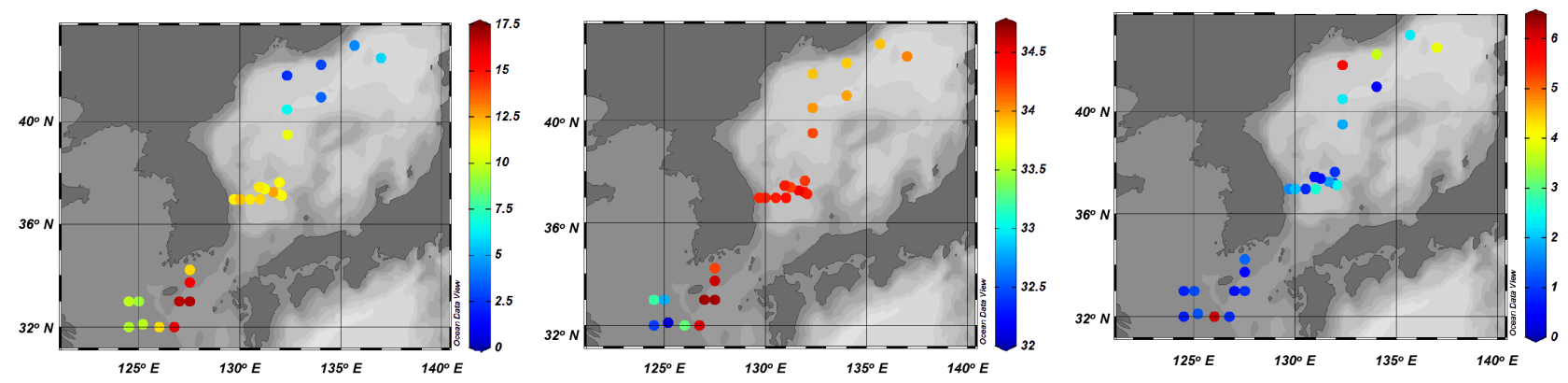

Fig. 2. Spatial distribution of seawater temperature, salinity, and chlorophyll $a(\mathrm{Chl} a)$ measured at the surface and subsurface $(\sim 20 \mathrm{~m})$ at each station.

\section{Distribution of Synechococcus clades in spring}

Picocyanobacteria displayed a well-defined composition pattern in spring (Fig. 3). Synechococcus was the most dominant picocyanobacteria during the study, and Prochlorococcus was not detected or negligible (data not shown). Although clade II Synechococcus was one of the dominant picocyanobacteria in the eastern part of the East China Sea, clades I and IV exclusively dominated at most stations. Furthermore, of the two clades, clade I was most abundant, accounting for at least $81 \%$ of Synechococcus populations in areas affected by coastal water. However, clade IV Synechococcus outnumbered clade I in the Ulleung Basin in the southwest East Sea, and reached an abundance of $30 \%$ of Synechococcus populations at station M10 on the subpolar front (Fig. 3).

The dominance of clade I was also apparent at the eastern stations in the East China Sea. However, the proportion of clade II, which is adapted to warm and oligotrophic water (Zwirglmaier et al. 2007) was high, accounting for up to $44 \%$ of picocyanobacterial sequences. The high percentage of clade II and higher seawater temperatures indicated an active inflow of oligotrophic warm water derived from the Kuroshio Current to the eastern part of the East China Sea. Synechococcus clades IX, XVII, WPC1, and
5.3-I/II were observed in a few samples, but did not exceed $3 \%$ of the total (data not shown).

Synechococcus clades I and IV have previously been observed to be dominant in the continental shelf of the East China Sea and Dokdo area around the Ulleung Basin in winter and spring (Choi et al. 2013, 2015a). In addition, they dominate in cold waters in the Arctic and Bering Sea, and coastal waters in the North Atlantic Ocean and northeast Pacific Ocean (Zwirglmaier et al. 2007, 2008, Huang et al. 2012, Sohm et al. 2016). Thus, they are considered to be adapted to cold and nutrient-rich water. However, the relative abundances of the two clades vary significantly both temporally and spatially. In a coastal area of San Diego, CA, the ratio of clade I and IV show seasonal variation (Tai and Palenik 2009), and in the Arctic Ocean, the distributions of the two clades are similar, but in the South Pacific and Eastern Atlantic Oceans, clade IV is more abundant (Zwirglmaier et al. 2008). However, clade I is more abundant than clade IV in coastal water in the northwestern Atlantic (Ahlgren and Rocap 2012). Although it has been shown that nitrate and iron concentrations and / or seawater temperature are controlling factors (Tai and Palenik 2009, Choi et al. 2013, Sohm et al. 2016), the mechanisms controlling the relative abundances of clades I and IV remain poorly understood. Similarly, in this study, we 

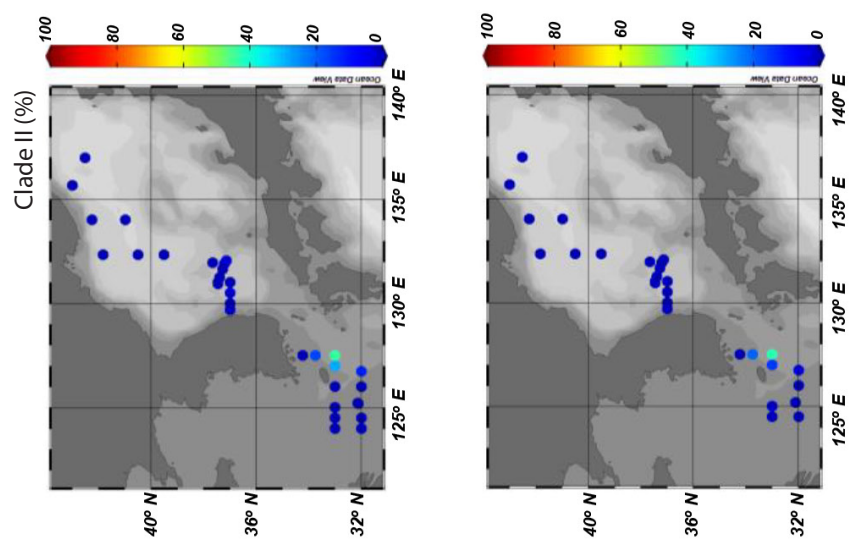

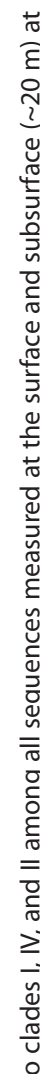
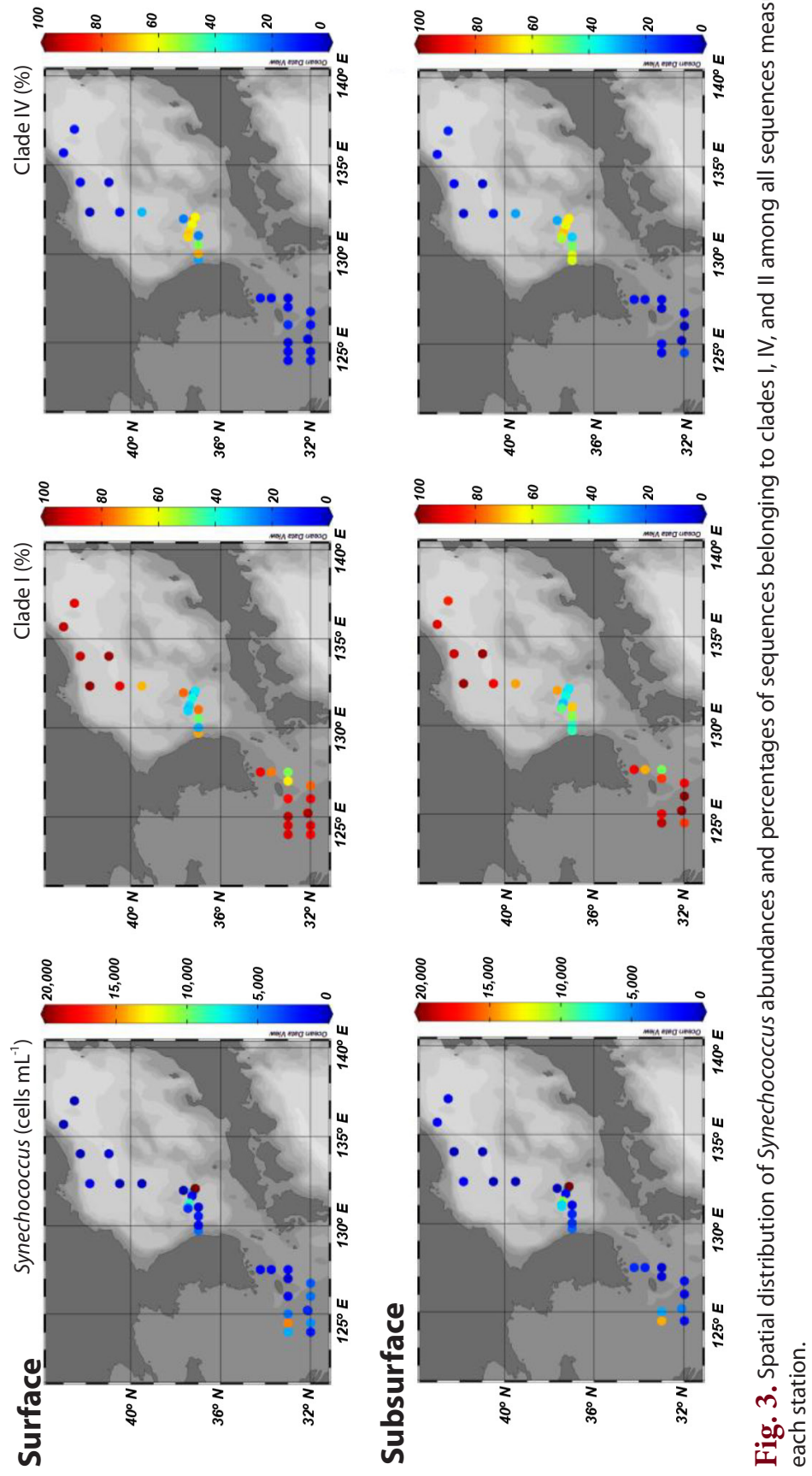


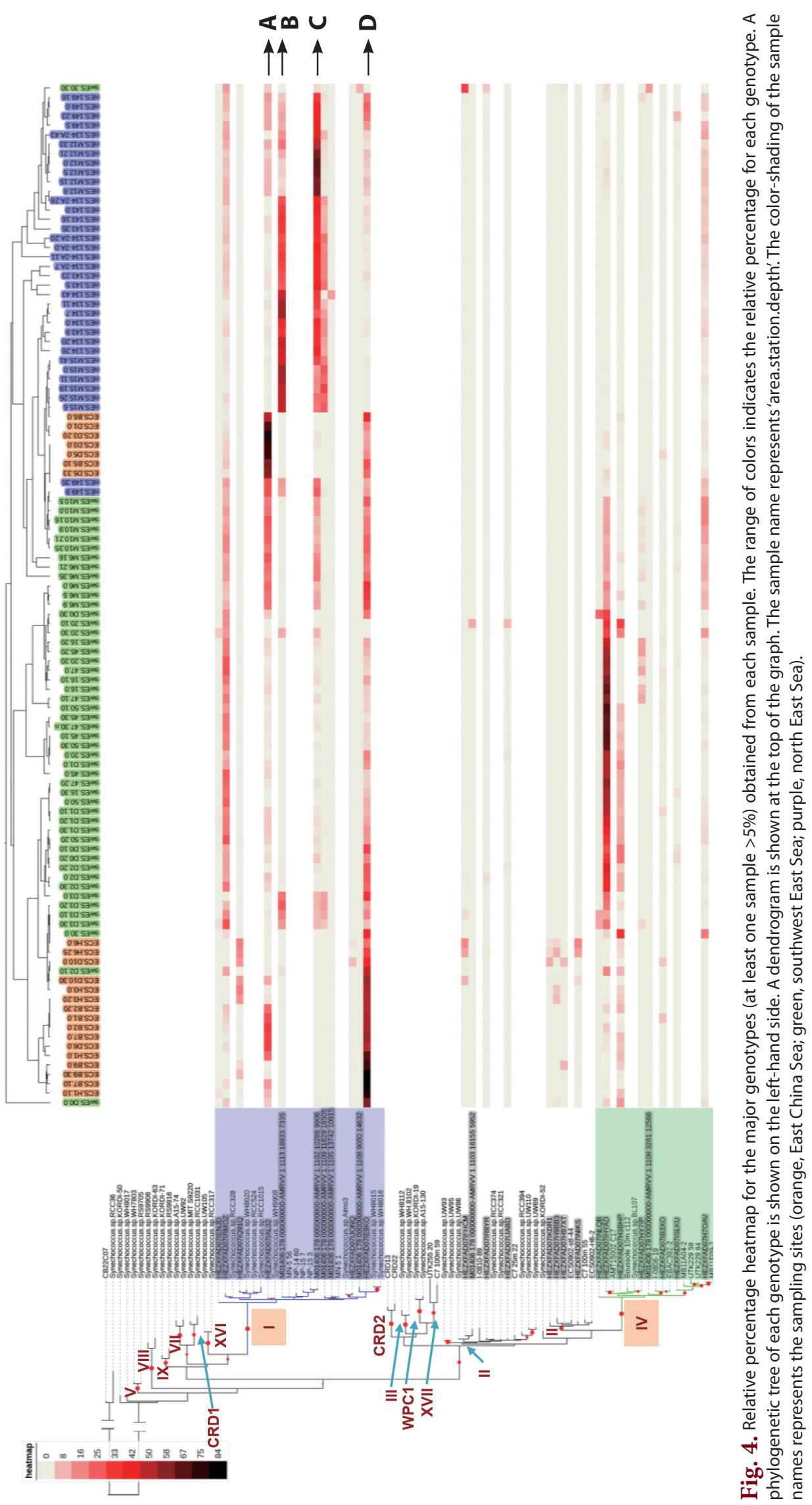



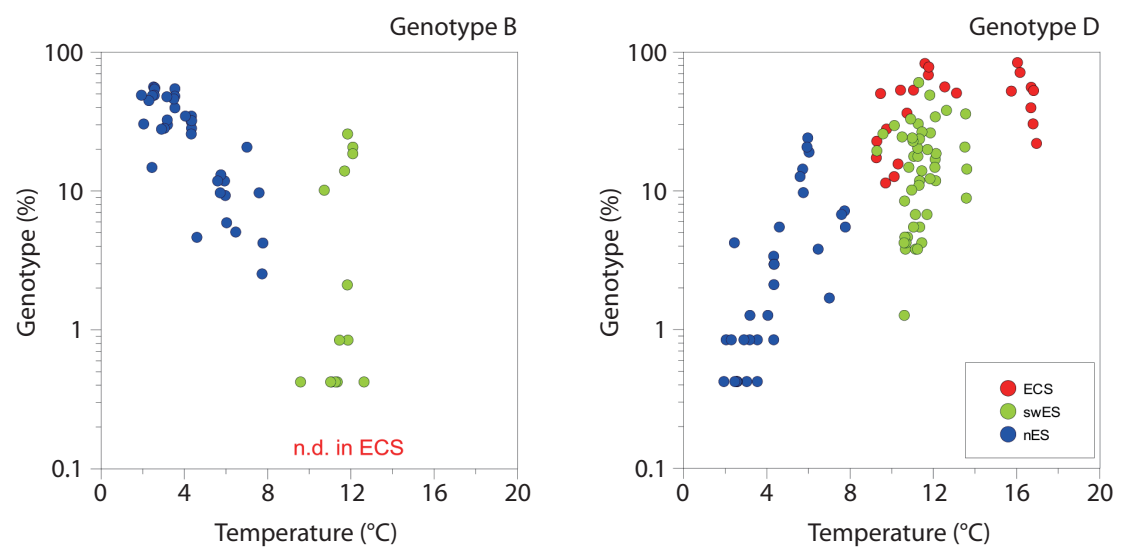

Fig. 5. Plots showing the relationships between sea temperature and percentage of genotype. Colors represent sampling areas (red, East China Sea [ECS]; green, southwest East Sea [swES]; blue, north East Sea [nES]). n.d., not detected.

were unable to identify any significant interrelationships between the relative abundances of clades I and IV versus environmental variables, including macronutrients, chlorophyll $a$, temperature, and salinity. However, clade I exclusively dominated in the areas affected by coastal water. Conversely, clade IV was comparable to or more abundant than clade I in areas affected by the Tsushima Warm Current originating from oligotrophic Kuroshio Current. This was consistent with a previous study conducted in the Dokdo area during winter and spring (Choi et al. 2015a). Thus, unknown and / or unmeasured characteristics related to coastal water input also appear to be important in controlling the relative abundances of the two clades. In fact, the isolates from the two clades have previously been clearly separated by genomic analyses into different groups (clade I as coastal / opportunists versus clade IV as open ocean / specialists) (Dufresne et al. 2008).

In the southwest East Sea, where clade IV was dominant, Synechococcus average abundances were $15.7 \times 10^{3}$ cells $\mathrm{mL}^{-1}$, which were 3-10-fold higher than in the other areas studied (Table 1). The rapid growth of clade IV Synechococcus might be related with the increase of Synechococcus abundance in spring in temperate waters.

\section{Different biogeographic distributions of clade I-genotypes}

Despite the geographic distance and different circulation systems between the East China Sea and the north East Sea, the picocyanobacterial compositions were very similar (Fig. 3). However, the spatial distributions of genotypes belonging to the same clade, differed signifi- cantly between the two areas (Fig. 4). Whereas genotype A was most dominant in the shelf area of the East China Sea as well as across the subpolar front, genotypes B and $\mathrm{C}$ dominantly occurred in the north East Sea and were frequently detected in the southwest East Sea. In contrast, genotype D was most dominant in the East China Sea and southwest East Sea, but was rarely found in the north East Sea. These different distributions were probably related to the current system in the East Sea, where two water masses from different sources meet and form the subpolar front along the $40^{\circ} \mathrm{N}$ latitude line. Genotype B was very dominant in the north East Sea, but was not detected in the East China Sea (Fig. 4). Genotype D, which was the dominant genotype in the East China Sea, was found at abundances up to approximately $30 \%$ in the north East Sea (Fig. 4). The East Korea Warm Current originating from the Tsushima Warm Current enters the north East Sea along the west coast of Japan (Lee et al. 2016). Thus, Synechococcus inhabiting the East China Sea can be transported to the subpolar area, where it will continue to multiply. However, the North Korea Cold Current originating from the Liman Current does not enter the East China Sea. Thus, this physical barrier between the two regions influences the presence/absence of specific genotypes.

The well-defined response to seawater temperature of some genotypes suggests that more than one ecotype is represented by each clade (Fig. 5). Despite genotypes B and $\mathrm{D}$ both belonging to clade $\mathrm{I}$, the relative percentages of each genotype showed the opposite responses to water temperature. This implies that one Synechococcus clade can be composed of different types of Synechococcus with different ecological niches. Using rpoCl (RNA poly- 
merase) gene probes with subclade-level resolution, Tai et al. (2011) showed that each Synechococcus sub-group had varying temporal and spatial dynamics, and suggested that Synechococcus sub-clades occupy different ecological niches. Consistent with this finding, a recent study using the high-resolution taxonomic marker petB, encoding cytochrome $b 6$, demonstrated ecologically meaningful fine-scale diversity within some Prochlorococus and Synechococcus ecotypes or clades (Farrant et al. 2016). The authors explained that clades II, CRD1, and EnvB, which are major Synechococcus clades, and other minor clades were composed of several ecologically significant taxonomic units with different ecological niches. However, they were unable to examine clade I due to a lack of data. Nonetheless, a phylogenetic analysis of petB gene sequences showed that clade I could be divided into three sub-groups (Mazard et al. 2012). Despite the fact that ITS phylogeny was unable to yield fine resolution comparable with petB, our data suggested that cold-adapted clade I would be composed of at least two sub-groups displaying different temperature responses.

As mentioned above, the factors regulating the relative abundances of different clades remains poorly understood. However, studies of Synechococcus biogeography using subclade-level genetic markers might be useful to identify the ecological niches of Synechococcus lineages.

\section{CONCLUSION}

In this basin-scale study, we determined the spatial diversity of picocyanobacteria in the East Sea and the East China Sea in spring. The cold-adapted Synechococcus clades I and IV were generally dominant in all study areas. However, the relative abundance of clades I and IV varied among regions. Furthermore, the regional distributions of the major genotypes within the same taxonomic group (clade I) differed significantly, and the patterns of their responses to seawater temperature also differed, suggesting the possibility that the cold-adapted clade I is composed of multiple ecotypes, each having different ecological niches. Despite the fact that we were unable to identify the specific factors involved due to the limited environmental data, the different environmental conditions due to the different physicochemical properties of the influencing water masses might play an important role in causing the distinct spatial distribution of coldadapted Synechococcus genotypes.

\section{ACKNOWLEDGEMENTS}

We would like to thank the crews of R/V Eardo and R/V Akademik M. A Lavertiev for their assistance during the cruises. This study was supported by research programs of the Korea Institute of Ocean Science and Technology (KIOST: PE99412, PE99414), and by fund provided by the Ministry of Oceans and Fisheries (PG49260).

\section{REFERENCES}

Ahlgren, N. A. \& Rocap, G. 2006. Culture isolation and culture-independent clone libraries reveal new marine Synechococcus ecotypes with distinctive light and N physiologies. Appl. Environ. Microbiol. 72:7193-7204.

Ahlgren, N. A. \& Rocap, G. 2012. Diversity and distribution of marine Synechococcus: multiple gene phylogenies for consensus classification and development of qPCR assays for sensitive measurement of clades in the ocean. Front. Microbiol. 3:213.

Choi, D. H. 2012. Picocyanobacterial diversity and distribution during summer in the northern East China Sea. Ocean Polar Res. 34:19-28. (In Korean).

Choi, D. H., An, S. M., Choi, Y. R., Roh, H. S. \& Noh, J. H. $2015 a$. Seasonal variation of picocyanobacterial community composition in seawaters around Dokdo, Korea. The Sea, J. Korean Soc. Oceanogr. 20:192-198. (In Korean).

Choi, D. H. \& Noh, J. H. 2009. Phylogenetic diversity of Synechococcus strains isolated from the East China Sea and the East Sea. FEMS Microbiol. Ecol. 69:439-448.

Choi, D. H., Noh, J. H. \& Lee, J. -H. 2014. Application of pyrosequencing method for investigating the diversity of Synechococcus subcluster 5.1 in open ocean. Microbes Environ. 29:17-22.

Choi, D. H., Noh, J. H. \& Shim, J. 2013. Seasonal changes in picocyanobacterial diversity as revealed by pyrosequencing in temperate waters of the East China Sea and the East Sea. Aquat. Microb. Ecol. 71:75-90.

Choi, D. H., Park, K. -T., An, S. M., Lee, K., Cho, J. -C., Lee, J. -H., Kim, D., Jeon, D. \& Noh, J. H. 2015b. Pyrosequencing revealed SAR116 clade as dominant $d d d P$-containing bacteria in oligotrophic NW Pacific Ocean. PLoS One 10:e0116271.

Choi, D. H., Selph, K. E. \& Noh, J. H. 2015c. Niche partitioning of picocyanobacterial lineages in the oligotrophic northwestern Pacific Ocean. Algae 30:223-232.

Choi, J. K., Noh, J. H., Orlova, T., Park, M. -O., Lee, S. H., Park, Y. -J., Son, S., Stonik, I. \& Choi, D. H. 2016. Phytoplankton and primary production. In Chang, K. -I., Zhang, C. -I., 
Park, C., Kang, D. -J., Ju, S. -J., Lee, S. -H. \& Wimbush, M. (Eds.) Oceanography of the East Sea (Japan Sea). Springer International Publishing, Cham, pp. 217-246.

Dufresne, A., Ostrowski, M., Scanlan, D. J., Garczarek, L., Mazard, S., Palenik, B. P., Paulsen, I. T., de Marsac, N. T., Wincker, P., Dossat, C., Ferriera, S., Johnson, J., Post, A. F., Hess, W. R. \& Partensky, F. 2008. Unraveling the genomic mosaic of a ubiquitous genus of marine cyanobacteria. Genome Biol. 9:R90.

Farrant, G. K., Doré, H., Cornejo-Castillo, F. M., Partensky, F., Ratin, M., Ostrowski, M., Pitt, F. D., Wincker, P., Scanlan, D. J., Iudicone, D., Acinas, S. G. \& Garczarek, L. 2016. Delineating ecologically significant taxonomic units from global patterns of marine picocyanobacteria. Proc. Natl. Acad. Sci. U. S. A. 113:E3365-E3374.

Fuller, N. J., Marie, D., Partensky, F., Vaulot, D., Post, A. F. \& Scanlan, D. J. 2003. Clade-specific 16S ribosomal DNA oligonucleotides reveal the predominance of a single marine Synechococcus clade throughout a stratified water column in the Red Sea. Appl Environ. Microbiol. 69:2430-2443.

Haverkamp, T., Acinas, S. G., Doeleman, M., Stomp, M., Huisman, J. \& Stal, L. J. 2008. Diversity and phylogeny of Baltic Sea picocyanobacteria inferred from their ITS and phycobiliprotein operons. Environ. Microbiol. 10:174188.

Huang, S., Wilhelm, S. W., Harvey, H. R., Taylor, K., Jiao, N. \& Chen, F. 2012. Novel lineages of Prochlorococcus and Synechococcus in the global oceans. ISME J. 6:285-297.

Illumina. 2013. 16S Metagenomic Sequencing Library Preparation. Available from: http://support.illumina.com/ downloads/16s_metagenomic_sequencing_library_ preparation.html. Accessed Dec 28, 2015.

Johnson, Z. I., Zinser, E. R., Coe, A., McNulty, N. P., Woodward, E. M. S. \& Chisholm, S. W. 2006. Niche partitioning among Prochlorococcus ecotypes along ocean-scale environmental gradients. Science 311:1737-1740.

Kim, K. -R., Lee, S. H., Park, K. -A., Park, J. J., Suh, Y. -S., Lee, D. -K., Kang, D. -J. \& Chang, K. -I. 2016. General Introduction. In Chang, K. -I., Zhang, C. -I., Park, C., Kang, D. -J., Ju, S. -J., Lee, S. -H. \&Wimbush, M. (Eds.) Oceanography of the East Sea (Japan Sea). Springer International Publishing, Cham, pp. 1-32.

Lavin, P., Gomez, P., González, B. \& Ulloa, O. 2008. Diversity of the marine picocyanobacteria Prochlorococcus and Synechococcus assessed by terminal restriction fragment length polymorphisms of 16S-23S rRNA internal transcribed spacer sequences. Rev. Chil. Hist. Nat. 81:515531.

Lavin, P., González, B., Santibáñez, J. F., Scanlan, D. J. \& Ulloa,
O. 2010. Novel lineages of Prochlorococcus thrive within the oxygen minimum zone of the eastern tropical South Pacific. Environ. Microbiol. Rep. 2:728-738.

Lee, D. -K., Seung, Y. H., Kim, Y. -B., Kim, Y. H., Shin, H. -R., Shin, C. -W. \& Chang, K. -I. 2016. Circulation. In Chang, K. -I., Zhang, C. -I., Park, C., Kang, D. -J., Ju, S. -J., Lee, S. -H. \& Wimbush, M. (Eds.) Oceanography of the East Sea (Japan Sea). Springer International Publishing, Cham, pp. 87-126.

Li, W. K. W. 1994. Primary production of prochlorophytes, cyanobacteria, and eukaryotic ultraphytoplankton: measurements from flow cytometric sorting. Limnol. Oceanogr. 39:169-175.

Liu, H., Nolla, H. A. \& Campbell, L. 1997. Prochlorococcus growth rate and contribution to primary production in the equatorial and subtropical North Pacific Ocean. Aquat. Microb. Ecol. 12:39-47.

Mazard, S., Ostrowski, M., Partensky, F. \& Scanlan, D. J. 2012. Multi-locus sequence analysis, taxonomic resolution and biogeography of marine Synechococcus. Environ. Microbiol. 14:372-386.

Mühling, M., Fuller, N. J., Somerfield, P. J., Post, A. F., Wilson, W. H., Scanlan, D. J., Joint, I. \& Mann, N. H. 2006. High resolution genetic diversity studies of marine Synechococcus isolates using rpoCl-based restriction fragment length polymorphism. Aquat. Microb. Ecol. 45:263-275.

Olson, R. J., Shalapyonok, A. \& Sosik, H. M. 2003. An automated submersible flow cytometer for analyzing picoand nanophytoplankton: FlowCytobot. Deep Sea Res. Part I Oceanogr. Res. Pap. 50:301-315.

Paerl, R. W., Foster, R. A., Jenkins, B. D., Montoya, J. P. \& Zehr, J. P. 2008. Phylogenetic diversity of cyanobacterial narB genes from various marine habitats. Environ. Microbiol. 10:3377-3387.

Parsons, T. R., Maita, Y. \& Lalli, C. M. 1984. A manual of chemical and biological methods for seawater analysis. Amsterdam, Pergamon, $188 \mathrm{pp}$.

Rocap, G., Distel, D. L., Waterbury, J. B. \& Chisholm, S. W. 2002. Resolution of Prochlorococcus and Synechococcus ecotypes using 16S-23S ribosomal DNA internal transcribed spacer sequences. Appl. Environmen. Microbiol. 68:1180-1191.

Schloss, P. D., Westcott, S. L., Ryabin, T., Hall, J. R., Hartmann, M., Hollister, E. B., Lesniewski, R. A., Oakley, B. B., Parks, D. H., Robinson, C. J., Sahl, J. W., Stres, B., Thallinger, G. G., Van Horn, D. J. \& Weber, C. F. 2009. Introducing Mothur: open-source, platform-independent, community-supported software for describing and comparing microbial communities. Appl. Environmen. Microbiol. 
75:7537-7541.

Sohm, J. A., Ahlgren, N. A., Thomson, Z. J., Williams, C., Moffett, J. W., Saito, M. A., Webb, E. A. \& Rocap, G. 2016. Cooccurring Synechococcus ecotypes occupy four major oceanic regimes defined by temperature, macronutrients and iron. ISME J. 10:333-345.

Stamatakis, A. 2006. RAxML-VI-HPC: maximum likelihoodbased phylogenetic analyses with thousands of taxa and mixed models. Bioinformatics 22:2688-2690.

Tai, V., Burton, R. S. \& Palenik, B. 2011. Temporal and spatial distributions of marine Synechococcus in the Southern California Bight assessed by hybridization to bead-arrays. Mar. Ecol. Prog. Ser. 426:133-147.

Tai, V. \& Palenik, B. 2009. Temporal variation of Synechococcus clades at a coastal Pacific Ocean monitoring site. ISME J. 3:903-915.

Toledo, G. \& Palenik, B. 1997. Synechococcus diversity in the California Current as seen by RNA polymerase (rpoC1) gene sequences of isolated strains. Appl. Environ. Microbiol. 63:4298-4303.

West, N. J., Lebaron, P., Strutton, P. G. \& Suzuki, M. T. 2011.
A novel clade of Prochlorococcus found in high nutrient low chlorophyll waters in the South and Equatorial Pacific Ocean. ISME J. 5:933-944.

West, N. J. \& Scanlan, D. J. 1999. Niche-partitioning of Prochlorococcus populations in a stratified water column in the eastern North Atlantic Ocean. Appl. Environ. Microbiol. 65:2585-2591.

Yue, J. C. \& Clayton, M. K. 2005. A similarity measure based on species proportions. Commun. Stat. Theory Methods 34:2123-2131.

Zwirglmaier, K., Heywood, J. L., Chamberlain, K., Woodward, E. M. S., Zubkov, M. V. \& Scanlan, D. J. 2007. Basin-scale distribution patterns of picocyanobacterial lineages in the Atlantic Ocean. Environ. Microbiol. 9:1278-1290.

Zwirglmaier, K., Jardillier, L., Ostrowski, M., Mazard, S., Garczarek, L., Vaulot, D., Not, F., Massana, R., Ulloa, O. \& Scanlan, D. J. 2008. Global phylogeography of marine Synechococcus and Prochlorococcus reveals a distinct partitioning of lineages among oceanic biomes. Environ. Microbiol. 10:147-161. 